\title{
Etika Penawaran Jual Beli dalam Telaah Hadits Ahkam
}

\author{
Sukma Sari Dewi Chan \\ IAIN Metro Lampung \\ sukmasari.dewichan@gmail.com
}

\begin{abstract}
How does Islam laid the foundations of supply ethics in buying and selling transactions? This question will be answered in this article by exploring the hadiths related to the basic principles and ethics of buying and selling in Islam. This ethic is endowed with buyers and sellers who seek to safeguard the interests and feelings of each party. These hadiths are tested using the بيع and keywords then grouped according to the subject matter. These hadiths are then analyzed to gain a complete understanding of the ethical buying and selling offerings in Islam.
\end{abstract}

Keywords: offer ethics, buy and sell, hadith ahkam

\begin{abstract}
Abstrak
Bagaimana Islam meletakkan dasar-dasar etika penawaran dalam transaksi jual beli? Pertanyaan inilah yang akan dijawab dalam artikel ini dengan mengupas hadits-hadits yang terkait dengan prinsip dan etika dasar penawaran jual beli dalam Islam. Etika ini terkat dengan pembeli dan penjual yang berupaya menjaga kepentingan dan perasaan masingmasing pihak. Hadits-hadits ini ditakhrij dengan menggunakan kata kunci سوم dan kemudian dikelompokkan berdasarkan objek bahasannya. Hadits-hadits ini kemudian dianalisis untuk mendapatkan pemahaman yang utuh terkait etika penawaran jual beli dalam Islam.
\end{abstract}

Kata Kunci: etika penawaran, jual beli, hadits ahkam

\section{A. Pendahuluan}

Mekanisme pasar pada dasarnya adalah pasar yang berjalan secara alami sesuai dengan fungsinya sebagai sara tempat bertemunya penjual dan pembeli, dan terjadinya interaksi anatara penawaran dan permintaan dengan berbagi atribut lainnya. Secara lebih spesifik, mekanisme pasar dapat dikatakan sebagai suatu pasar yang berjalan tanpa 
adanya campur tangan dari pihak manapun untuk mempenagruhi permintaan, penawaran, maupun harga di dalamnya. ${ }^{1}$

Penawaran dalam jual beli terutama yang konvensional merupakan suatu proses yang tidak dapat dihindarkan. Hal itu disebabkan adanya dua kepentingan yang saling bertolak belakang. Pihak penjual tentu saja mengingankan untuk dapat menjual barangnya dengan harga tinggi. Sedangkan di satu sisi, pihak pembeli tentu saja menginginkan dapat membeli barang dengan harga yang rendah. ${ }^{2}$

Keinginan antara penjual dan pembeli ini sering menimbulkan konflik, untuk meminimalisir konflik yang terjadi Rasulullah telah menjelaskan mengenai etika penawaran di dalam hadis. Oleh karena itu, dalam tulisan ini penulis akan menjelaskan tentang Etika Penawaran dalam Jual Beli Perspektif Hadis

\section{B. Etika dalam Jual Beli}

\section{Etika}

Etika atau ethics berasal dari bahasa Inggris yang mengandung banyak pengertian. Dari segi etimologi, istilah etika berasal dari bahasa latin ethius (dalam bahasa Yunani adalah ethicos) yang berarti kebiasaan(custom) atau karakter ${ }^{3}$ pengertian ini lambat laun berubah menjadi suatu ilmu yang membicarakan masalah perbuatan atau tingkah laku manusia, mana yang dapat dinilai baik dan mana yang tidak. Sedangkan dari segi terminologi, etika merupakan aturan-aturan konvensional mengenai tingkah laku individual dalam masyarakat beradab, tata cara formal atau tata krama lahir untuk mengatur hubungan antar pribadi, sesuai dengan status sosial masing-masing.

2. Jual Beli

a. Pengertian

\footnotetext{
${ }^{1}$ Isnaini Harahap, Hadis-Hadis Ekonomi, (Jakarta: Prenadamedia Group, 2015), cet 1, h. 165

${ }^{2}$ Enizar, Hadis Ekonomi, (Jakarta: PT Raja Grafindo Persada, 2013), h. 128

${ }^{3}$ Faisal Badroen dkk, Etika Bisnis dalam Islam, (Jakarta;Kencana.2007) h. 4
} 
Jual beli dalam istilah fiqh disebut dengan اليع yang berarti menjual, mengganti, dan menukar sesuatu dengan sesuatu yang lain. ${ }^{4}$ Secara terminologi ialah tukar menukar harta dengan harta yang dimaksudkan untuk suatu kepemilikan, yang ditunjukkan dengan perkataan dan perbuatan

b. Rukun dan syarat jual beli

1) Rukun Jual beli

Menurut jumhur ulama rukun jual beli ada empat yaitu,

a) Ada orang yang berakad (penjual dan pembeli)

b) Ada shighat (lafal ijab kabul)

c) Ada barang yang dibeli

d) Ada nilai tukar pengganti barang.

2) Syarat-syarat jual beli

Adapun syarat jual beli berdasarkan rukun jual beli yang dikemukakan jumhur ulama di atas adalah sebagai berikut:

a) Syarat orang yang berakad

1. Berakal. Oleh sebab itu, jual beli yang dilakukan anak kecil yang belum berakal dan orang gila, hukumnya tidak sah.

2. Orang yang melakukan akad adalah orang yang berbeda, artinya seseorang tidak dapat bertindak dalam waktu bersamaan sebagai penjual sekaligus pembeli.

b) Syarat yang terkait dengan ijab dan qabul

1. Orang yang mengucapkannya telah baligh dan berakal

2. Qabul sesuai dengan ijab

\footnotetext{
${ }^{4}$ Nasrun Harun, Fiqh Muamalah, (Jakarta: Gaya Media Pratama, 2007), h. 111
} 
3. Ijab qabul itu dilakukan dalam satu majlis artinya kedua belah pihak yang melakukan jual beli hadir dan membicarakan topik yang sama

c) Syarat barang yang diperjualbelikan

1. Barang yang diperjualbelikan ada atau tidak ada di tempat tetapi pihak penjual menyatakan kesanggupan untuk mengadakan barang tersebut

2. Dapat dimanfaatkan dan bermanfaat bagi manusia

3. Milik seseorang

4. Boleh diserahkan pada saat akad berlangsung, atau pada waktu yang disepakati bersama ketika transaksi berlangsung

d) Syarat-syarat nilai tukar

1. Harga yang disepakati kedua belah pihak harus jelas

2. Boleh diserahkan pada waktu akad, apabila harga barang itu dibayarkan kemudian maka waktu pembayarannya harus jelas

3. Apabila jualbeli itu dilakukan dengan saling mempertukarkan barang maka barang yang dijadikan nilai tukar bukan barang yang haram

Dalam jual beli tidak hanya memperhatikan rukun dan syarat jual beli saja tetapi juga persoalan etika dalam pelaksanaan transaksi jual beli. Jadi yang dimaksud dengan etika dalam jual beli adalah tata cara atau prilaku yang ditanamkan di dalam diri seorang penjual dan pembeli dalam melakukan transaksi tukar menukar barang dengan tujuan saling tolong menolong antara yang satu dengan yang lain.

Salah satu etika yang harus ditanamkan oleh penjual dan pembeli adalah tidak saling menyayangi antara penjual atau pembeli dengan penjual atau pembeli lainnya. Setiap pedagang pasti ingin mencari keuntungan bahkan kalau perlu melakukan berbagai cara. Banyak orang yang terjebak dengan melakukan perbuatan tidak terpuji, misalnya dengan cara menjelek-jelekkan dagangan orang lain, sehingga bisnis pesaingnya jatuh 
reputasinya. Akibatnya pelanggan lari dan berpindah sendirinya. Menyaingi pedagang lain dengan menjelek-jelekkan merupakan tidakan pengecut. Islam membenarkan adanya persaingan usaha dan melarang praktik monopoli. Persaingan dalam jual beli berdampak positif jika dilakukan dengan cara-cara yang terpuji. Misalnya dengan cara memberikan pelayanan terbaik kepada konsumen, seperti menjual barang yang berkualitas baik tetapi dengan harga yang murah, memberikan penjelasan tentang manfaat dari produk yang dijualnya dari sisi baik dan buruknya, bersikap ramah kepada konsumen, memberi kenyamanan kepada konsumen saat mereka berbelanja, memberikan bonus kepada konsumen yang memborong produk kita dan lain sebagainya. ${ }^{5}$

Dalam dunia perdagangan, dasar persaingan adalah kemampuan mengikat hati penjual dan pembeli di pasar sehingga membuat konsumen terus meminta, membeli dan menggunakan produk atau jasa yang ditawarkan, bukan dari penjual lainnya. ${ }^{6}$

\section{Pemahaman Hadis (Fiqh-al-Hadis)}

Pemahaman, dalam Bahasa Arab disebut dengan fiqh yang secara bahasa berarti mengetahui sesuatu dan memahaminya. ${ }^{7}$ Sedangkan dalam Kamus Besar Bahasa Indonesia, pemahaman berasal dari kata paham, yang bermakna pandangan, pengertian, pendapat, pikiran, haluan, mengerti benar, tahu benar atau pandai dan mengerti benar tentang suatu hal. Sedangkan pemahaman bermakna proses, perbuatan, cara memahami. ${ }^{8}$

Dari pengertian beberapa kata di atas, maka pemahaman hadis dapat dirumuskan sebagai tata cara yang bersifat ilmiah untuk menggali dan memahami ajaran-ajaran agama berupa kehendak atau pesan-pesan Rasulullah dengan tepat yang terkandung di dalam hadis-hadis yang diriwayatkan dari beliau.

\footnotetext{
${ }^{5}$ Ahmad Dahlan (tesis), Penerapan Etika Jual Beli dalam Islam di Pasar Tradisional Air Tiris, 2012, h. 45 h. 113

${ }^{6}$ Muhammad Ali Haji Hasim, Bisnis Satu Cabang Jihad, (Jakarta, Pustaka Al-Kausar, 2005),

${ }^{7}$ Maizuddin, Metodologi Pemahaman Hadis, (Padang: Hayfa Press, 2008), 13

8 Tim Prima Pena, Kamus Besar Bahasa Indonesia, (t.tp: Gitamedia Press, t.th), h. 721
} 
Dilihat dari kecendrungan ulama dalam memahami hadis, maka metode pemahaman hadis dapat diklasifikasikan ke dalam dua bentuk metode, yaitu metode pemahaman hadis tradisionalis dan metode pemahaman hadis modernis

1. Metode Pemahaman Hadis Tradisionalis

Metode pemahaman hadis tradisionalis adalah memahami hadis dengan pendekatan tekstual. ${ }^{9}$ Menurut penulis yang dimaksud dengan metode pemahaman hadis tradisionalis adalah pemahaman hadis yang hanya merujuk kepada makna zahir hadis saja atau hanya merujuk kepada pemahaman ulama yang lama dan sudah bangga dengan pendapat ulama yang lama tersebut tanpa adanya keberanian untuk memberikan pendapat sendiri atau mengkritisi pendapat yang lama. Seakan-akan tidak memiliki kepercayaan diri untuk mengeluarkan pendapat dan mengkritisi. Metode pemahaman tradisionalis dapat dipilah kepada metode analitis, metode global, dan metode komparatif.

\section{Metode Pemahaman Hadis Modernis}

Metode pemahaman hadis modernis adalah memahami hadis-hadis Rasulullah dengan pendekatan ilmiah dan logika deduktif (filosofis). ${ }^{10}$ Menurut analisis penulis metode pemahaman hadis modernis adalah metode dalam memahami hadis dengan tidak meninggalkan pendapat yang lama tetapi tetap mempertahankannya sebagai pertimbangan dengan mengeluarkan pendapat yang baru. Jika setuju dengan pendapat ulama tradisional mereka menjelaskan kenapa hal ini cocok dengan zaman sekarang dan zaman yang akan datang.

Metode pemahaman hadis modernis ini dapat dipilah menjadi memahami hadis Rasul dengan pendekatan ilmiah dan logika deduktif (filosofis), pendekatan tematis korelatif.

\footnotetext{
${ }^{9}$ Buchari M, Metode Pemahaman Hadis, Sebuah Kajian Hermenetik, (Jakarta: Nuansa Madani, 1999), cet I, h. 26

${ }^{10}$ Ibid, h. 52
} 
Metode yang dipakai dalam artikel ini adalah metode pemahaman hadis modernis dengan menggunakan pendekatan tematis korelatif yaitu mengumpulkan hadis-hadis dalam satu tema (hadis tentang etika penawaran) kemudian menggali pemahaman hadis-hadis tersebut agar diperoleh pemahaman yang utuh.

\section{Hadis-Hadis Ahkam tentang Etika Penawaran}

1. Pelacakan Hadis

Untuk melacak hadis-hadis yang berkaitan dengan etika penawaran penulis menggunakan kitab al-Mu'jam al-Mufahras li Alfazh al-Hadis al-Nabawi karya A.J Weinsink. Kata yang penulis lacak adalah بيع penulis mendapatkan informasi bahwa katakata tersebut terdapat di dalam kitab Mu'jam jilid 1 halaman $245 .{ }^{11}$ Berdasarkan informasi mu'jam informasi mengenai hadis yang penulis dapatkan adalah:

Shahih al-Bukhari

1) kitab buyu’ bab 58, 64, 10, 71

2) kitab Syuruth bab 8

3) kitab Nikah bab 45

Shahih Muslim

1) kitab Nikah bab 49

2) kitab Buyu' bab 7, 8, 11

3) kitab Birr bab 29, 32

Sunan Abu Daud

1) kitab Nikah bab 16

2) kitab Buyu' bab 43, 46

Sunan al-Tirmidzi

1) Kitab Nikah bab 38

2) Kitab Виуu; bab 57

Sunan al-Nasai

1) Kitab Nikah bab 20, 21

2) Kitab Buyu' bab 17, 20, 21

${ }^{11}$ A. J Wensinck, al-Mu'jam al-Mufahras li Alfaz al-Hadis al-Nabawi, (Leiden: E. J. Brill, 1943 \& 1962), Jilid 1, h. 245 
Sunan Ibn Majah

Sunan al-Darimi

Al-Muwatha

Musnad Ahmad bin Hanbal
1) Kitab Tijarat bab 13

1) Kitab Nikah bab 6

2) Kitab Buyu’ bab 17, 33

1) Kitab Вuyu' bab 95, 96

1) Jilid 2, halaman 7, 21, 63, 71, 107, 122, 124, 126, 130, 146, 153, 237, 243, 254, 274, 277, 311, 317, 360, 370, 394, 402, 410, 420, 465, 481, $484,487,491,501,506,525$

2) Jilid 4, halaman 137

Untuk mendapatkan informasi yang luas terhadap hadis penulis juga melakukan pelacakan terhadap kata سوم penulis mendapatkan informasi bahwa kata-kata tersebut terdapat di dalam kitab Mu'jam jilid 3 halaman $239 .{ }^{12}$ Informasi yang penulis temukan adalah sebagai berikut:

Shahih al-Bukhari

Shahih Muslim

Sunan al-Tirmidzi

Sunan Ibn Majah

Musnad Ahmad bin Hanbal
Kitab Buyu’ bab 58

1) Kitab Nikah bab $38,15,45,55$

2) Kitab Buyu’ bab 9

Kitab Buyu’ 57

Kitab Tijarat bab 13

1) Jilid 3, halaman 394, 411, 427, 457, $463,489,508,512,516,569$

2) Jilid 2, halaman 411

\footnotetext{
${ }^{12}$ Ibid, jilid 3, h. 39
} 
2. Klasifikasi Hadis

Setelah penulis melakukan pelacakan terhadap hadis, maka selanjutnya penulis mengelompokkan hadis-hadis tersebut berdasarkan pembahasan yang sama.

a. Hadis tentang etika penawaran bagi si pembeli

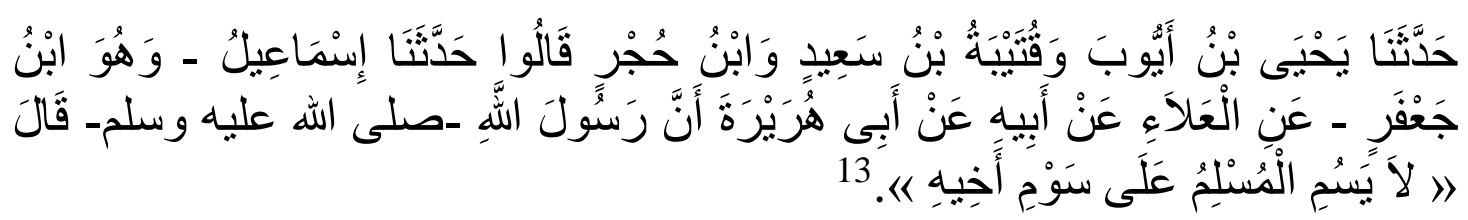

Artinya, menceritakan kepada kami Yahya bin Ayyub dan Qutaibah bin Said dan Ibn Hujr mereka berkata menceritakan kepada kami Ismail (Ibn Ja'far) dari al-A'lai dari bapaknya dari Abi Hurairoh bahwasannya Rasululah SAW bersabda "janganlah seorang muslim menawar barang yang ditawar oleh saudaranya (muslim lainnya)”. (HR. Muslim)

b. Hadis tentang etika penawaran bagi si penjual

$$
\begin{aligned}
& \text { حدثنا إسماعيل فال حدثني مالك عن نافع عن عبد الله بن عمر رضي الله عنهما : أن } \\
& \text { رسول الله صلى الله عليه و سلم قال ( لا بييع أحدكم على بيع أخيه ) } 14
\end{aligned}
$$

Artinya, menceritakan kepada kami Ismail berkata menceritakan kepadaku Malik dari Nafi' dari Abdullah bin Umar ra, bahwa Rasulullah SAW berkata" janganlah seseorang di antara kamu menjual barang yang dijual oleh saudaranya”. (HR. Bukhari)

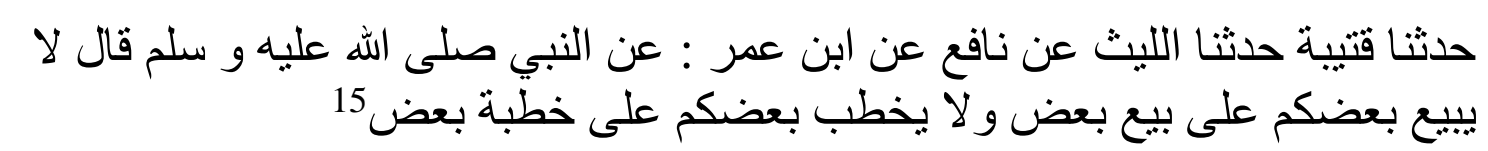

Artinya, menceritakan kepada kami Qutaibah menceritakan kepada kami al-Lais dari Nafi' dari Ibn Umar dari Nabi SAW berkata: " janganlah sebagian kamu menjual barang sedang dijual oeleh sebagian yang lain, dan janganlah sebagian kamu meminang pinangan yang lain”.(HR. Tirmidzi)

c. Hadis pengecualian

\footnotetext{
${ }^{13}$ Shahih Muslim, (Maktabah Syamilah)

${ }^{14}$ Abi Abdillah Muhammad bin Ismail bin Ibrahim bin al-Mughairah bin Bardizbah al-Bukhari alJa'fari, Shahih al-Bukhari, (Beirut: Daar al-Kutub al-Ilmiyah, 2007), h. 99

${ }^{15}$ Sunan al-Tirmidzi (Maktabah Syamilah)
} 


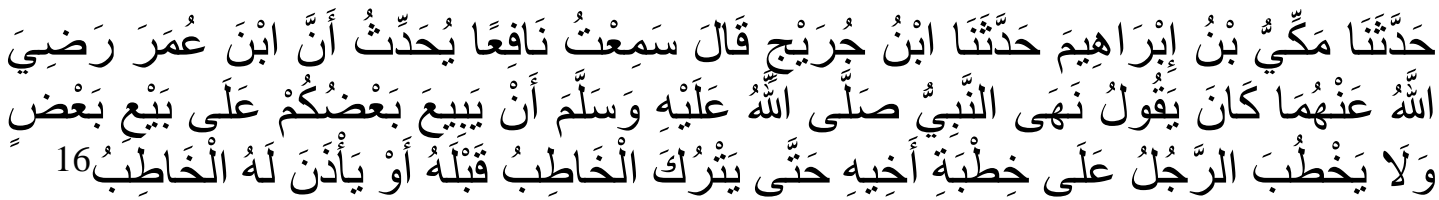

Artinya, Telah menceritakan kepada kami Makki bin Ibrahim Telah menceritakan kepada kami Ibnu Juraij ia berkata, Aku mendengar Nafi' menceritakan bahwa Ibnu Umar radliallahu 'anhuma berkata, "Nabi shallallahu 'alaihi wasallam telah melarang sebagian kalian untuk berjual beli atas jual beli saudaranya. Dan janganlah seseorang meminang atas pinangan yang lain hingga ia meninggalkannya atau pun menerimanya, atau pun ia telah diberi izin oleh sang peminang pertama."(HR. Bukhari)

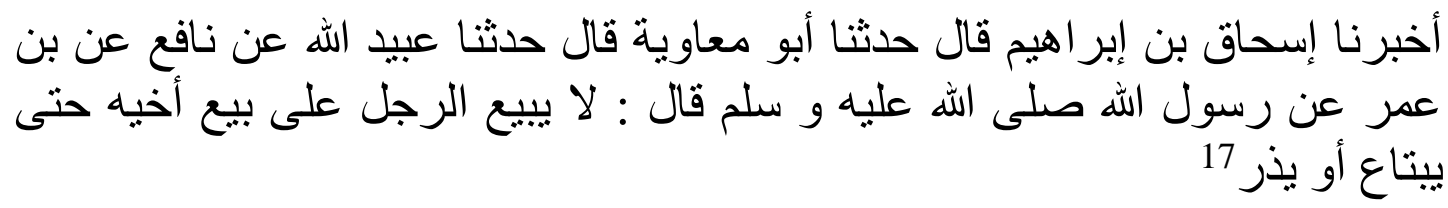

Artinya, mengabarkan kepada kami Ishaq bin Ibrahim berkata menceritakan kepada kami Abu Muawiyah berkata menceritakan kepada kami ubaidillah dari Nafi' dari Ibn Umar dari Rasulullah SAW bersabda: “ Janganlah kamu membeli sesuatu yang dibeli oleh saudaramu sampai ia membeli atau meninggalkannya”. (HR. Al-Nasa'i)

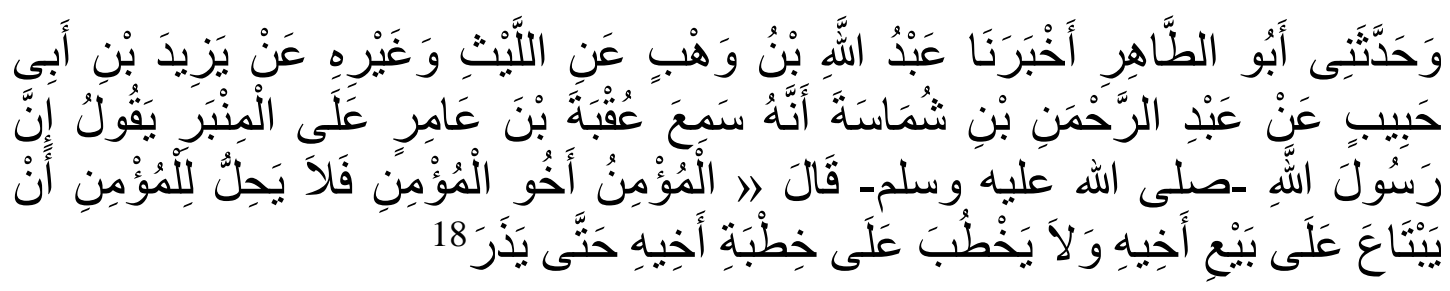

Artinya, dan menceritakan kepadaku al-Thahir mengabarkan kepada kamu Abdullah bin Wahb dari al-Lais dan yang lainnya dari Yazid abi Habib dari Abdurrahman bin Syumasah bahwasannya mendengar Uqbah bin Amir di atas mimbar sesungguhnya Rasululullah SAW bersabda "seorang mukmin adalah saudara dari mukmin lainnya maka tidak halal seorang mukmin menjual atas penjual saudaranya dan janganlah meminang di atas pinangan saudaranyya sampai ia meninggalkannya. "(HR. Muslim)

\section{E. Pemahaman Hadis tentang Etika Penawaran}

1. Etika penawaran bagi si pembeli

\footnotetext{
${ }^{16}$ Abi Abdillah Muhammad bin Ismail bin Ibrahim bin al-Mughairah bin Bardizbah al-Bukhari alJa'fari, Op.,cit, h. 99

${ }^{17}$ Sunan al-Nasa'i (Maktabah Syamilah)

${ }^{18}$ Shahih Muslim (Maktabah Syamilah)
} 
Hadis riwayat Muslim di atas menyatakan larangan bagi seorang pembeli menawar apa yang sedang ditawar oleh pembeli lainnya. Bagi calon pembeli praktik menawar tawaran orang lain yang melanggar etika penawaran di dalam hadis di atas adalah:

a. Calon pembeli kedua memberikan penawaran harga lebih tinggi dari penawar pertama yang sedang proses tawar menawar dengan penjual atau pembeli lain atau pada jual beli yang masih pada masa khiyar ${ }^{19}$

Contohnya: Ahmad sedang melakukan tawar menawar dengan seorang penjual tas di sebuah pasar, sedang berlangsung proses tawar-menawar tersebut tiba-tiba Anshar menawar tas yang sedang ditawar Ahmad dengan harga yang lebih tinggi dari harga Ahmad, dengan tujuan agar si penjual membatalkan transaksinya dengan Ahmad dan beralih kepada Anshar.

b. Calon pembeli kedua meminta kepada penjual yang sedang masa khiyar untuk membatalkan jual beli dengan pembeli pertama dengan memberikan janji akan membeli harga yang lebih tinggi.

Contohnya Pak Raden sedang dalam proses tawar menawar dengan seorang penjual tas di pasar, Pak Raden belum memutuskan apakah ia jadi membeli atau tidak, sedang dalam proses tersebut Pak Saiful mendatangi si penjual. Pak Saiful meminta agar si penjual membatalkan transaksinya dengan Pak Raden, jika si penjual membatalkan transaksi tersebut Pak Saiful berjanji akan membeli harga tas tersebut dua kali lipat dari harga yang ditawarkan Pak Raden.

c. Penawaran terhadap tawaran orang lain ketika calon pembeli kedua menyatakan kekurangan barang yang sedang ditawar oleh calon pembeli pertama. Cara ini

\footnotetext{
${ }^{19}$ Enizar,op., cit, h. 129
} 
dilakukan dengan maksud agar penawar pertama tidak jadi membeli barang tersebut dan pembeli kedua bermaksud untuk membelinya. ${ }^{20}$

Contohnya, Pak Syahid sedang melakukan penawaran tas di toko Pak Adam, sedang berlangsungnya proses tawar menawar tersebut, datanglah Pak Wahid menyatakan kejelekan dari tas yang sedang ditawar Pak Syahid misalnya dengan menyatakan" Jangan beli tas ini pak, saya kemaren beli tas yang sama baru dua hari dipakai resletingnya copot.'karena pernyataan Pak Wahid tersebut Pak Syahid mengurungkan niatnya untuk melanjutkan pembelian tas tersebut. Setelah Pak Syahid meninggalkan tempat transaksi Pak Wahid dengan segera membeli tas yang sedang ditawar Pak Syahid tadi.

2. Etika Penawaran bagi si Penjual

Etika penawaran tidak hanya berlaku bagi si pembeli saja tapi juga berlaku bagi si penjual sebagaimana yang tertera di dalam hadis riwayat Bukhari dan al-Tirmidzi di atas. Bagi penjual, praktik yang melanggar etika penawaran tersebut dapat berbentuk menawarkan barang dagangan dengan harga yang lebih rendah kepada calon pembeli yang sedang proses tawar menawar dengan penjual lain. Praktik tersebut dapat juga berbentuk menawarkan barang yang kualitasnya lebih baik dengan harga yang sama kepada calon pembeli yang sedang proses tawar-menawar atau pada masa khiyar dengan penjual lain. ${ }^{21}$

Contohnya, Pak Amin seorang penjual tas sedang melakukan tawar-menawar dengan seorang pembeli, sedang proses tawar-menawar Pak Ali sebagai penjual tas lain juga menawarkan tas kepada si pembeli tersebut dengan harga yang lebih rendah, dengan tujuan agar si pembeli membatalkan tawar menawar dengan Pak Amin dan beralih kepada Pak Ali. contoh di atas terlihat bahwa adanya upaya dari penjual

${ }^{21}$ Ibid, h. 129 
kedua untuk merayu pembeli agar membatalkan transaksinya dengan penjual pertama. Praktek ini dilarang, karena hal ini menimbulkan kebencian dan permusuhan disebabkan penyerobotan terhadap rezeki orang lain. ${ }^{22}$

Larangan menjual barang yang sedang dijual oleh penjual lain di dalam hadis tersebut (hadis riwayat al-Tirmidzi) juga beriringan dengan larangan meminang perempuan yang sedang dalam pinangan orang lain. Hal ini untuk mengantisipasi terjadinya konflik dan pertengkaran antara sesama muslim dan juga persaingan yang tidak sehat di antara keduanya. Larangan ini juga menegaskan agar pihak yang datang belakangan menghormati dan menghargai pihak yang sebelumnya.

3. Pengecualian

Pengecualian berdasarkan hadis di atas (hadis riwayat Bukhari, Muslim, dan alNasa'i) adalah penjual atau pembeli kedua diperbolehkan menawarkan barang yang sedang ditawar orang lain ketika penjual pertama dan pembeli pertama memberikan izin terhadap hal tersebut atau penjual dan pembeli pertama menyelesaikan transaksi tersebut dengan membelinya atau meninggalkannya. Begitu juga dengan meminang perempuan yang telah dipinang orang lain, apabila peminang pertama telah memutuskan pinangannya maka peminang kedua baru memiliki hak untuk meminang perempuan tersebut.

Menurut Imam Ahmad jual beli seperti ini tidak sah, tidak dapat dilaksanakan, karena adanya larangan untuk itu dan karena adanya kerugian. ${ }^{23}$ Pendapat ini berdasarkan tidak terpenuhinya rukun dan syarat dalam transaksi jual beli dan juga sebab merugikan pihak lain lain. Sedang menurut tiga Imam lainnya menyatakan jual belinya sah sebab larangan itu tidak pada transaksinya tapi masalah dari individu yang

\footnotetext{
${ }^{22}$ Abdullah bin Abdurrahman Alu Bassam, Syarh Hadis Pilihan Bukhari-Muslim, Judul Asli, Taisirul -Allam Syarh Umdatul Ahkam, penerjemah: Kathur Suhardi, (Jakarta: Darul Falah, 2002), h. 680

${ }^{23}$ Ibid, h. 684
} 
bertransaksi tersebut. ${ }^{24}$ Maksudnya rukun dan syarat jual belinya terpenuhi hanya saja sikap tidak menghargai dan persaingan tidak sehat dalam transaksi tersebut yang menimbulkan larangan.

\section{Simpulan}

Berdasarkan uraian di atas dapat disimpulkan bahwa dalam melakukan transaksi jual beli ada beberapa hal yang harus diperhatikan salah satunya etika dalam penawaran. Etika penawaran ini berlaku baik untuk penjual maupun pembeli. Berdasarkan hadis di atas dilarang bagi penjual menjual barang yang sedang dijual oleh penjual lainnya, begitu juga pembeli dilarang menawar barang yang sedang ditawarkan orang lain. Hal ini untuk menghindari terjadinya konflik dan perpecahan ketika melakukan transaksi jual beli. Dalam Hadis lain, Rasulullah juga menerangakan adanya pengecualian, maksudnya dibolehkan menjual atau menawar barang yang sedang dijual atau ditawar orang lain apabila penjual atau pembeli pertama membatalkan jual beli dan mengizinkan penjual atau pembeli pertama melakukan transaksi jua beli.

\section{Daftar Pustaka}

al-Ja'fari , Abi Abdillah Muhammad bin Ismail bin Ibrahim bin al-Mughairah bin Bardizbah al-Bukhari, (2007), Shahih al-Bukhari, Beirut: Daar al-Kutub al-Ilmiyah

Alu Bassam, Abdullah bin Abdurrahman, ( 2011), Syarah Hadis Pilihan (Bukhari-Muslim), penerjemah: Kathur Suhardi, judul asli: Taisirul Allam Syarh Umdatul Ahkam, Bekasi: PT Darul Falah, cet 10, edisi revisi

Badroen, Faisal dkk, (2007), Etika Bisnis dalam Islam, Jakarta;Kencana

Dahlan, Ahmad, (2012), Penerapan Etika Jual Beli dalam Islam di Pasar Tradisional Air Tiris (tesis) UIN RIAU

Enizar, (2013), Hadis Ekonomi, Jakarta: PT Raja Grafindo Persada

\footnotetext{
${ }^{24}$ Ibid, h. 684
} 
Harahap, Isnaini, (2015), Hadis-Hadis Ekonomi, Jakarta: Prenadamedia Group, cet 1

Harun, Nasrun, (2007), Fiqh Muamalah, Jakarta: Gaya Media Pratama

Hasim , Muhammad Ali Haji,(2005), Bisnis Satu Cabang Jihad, Jakarta, Pustaka Al-Kausar

M , Buchari, (1999), Metode Pemahaman Hadis, Sebuah Kajian Hermenetik, Jakarta: Nuansa Madani, cet I

Maizuddin, (2008), Metodologi Pemahaman Hadis, Padang: Hayfa Press

Shahih Muslim (Maktabah Syamilah)

Shahih Muslim, (Maktabah Syamilah)

Sunan al-Nasa'i (Maktabah Syamilah)

Sunan al-Tirmidzi (Maktabah Syamilah)

Tim Prima Pena, (t.th), Kamus Besar Bahasa Indonesia, t.tp: Gitamedia Press

Wensinck , A. J, (1943\&1962), al-Mu'jam al-Mufahras li Alfaz al-Hadis al-Nabawi, Leiden: E. J. Brill 